\title{
SOME REVERSES OF THE CAUCHY-SCHWARZ INEQUALITY FOR COMPLEX FUNCTIONS OF SELF-ADJOINT OPERATORS IN HILBERT SPACES
}

\author{
S. S. Dragomir, M. S. Moslehian And Y. J. ChO
}

Abstract. We give some ratio and difference reverses of the Cauchy-Schwarz inequality for complex functions of self-adjoint operators in Hilbert spaces, under suitable assumptions for the involved operators. Several examples for particular functions of interest are provided as well.

Mathematics subject classification (2010): 47A63, 47A99.

Keywords and phrases: Self-adjoint operators, reverse of the Cauchy-Schwarz inequality, spectral representation, functions of self-adjoint operators.

\section{REFERENCES}

[1] Lu. Arambasić, D. Bakić And M. S. Moslehian, A treatment of the Cauchy-Schwarz inequality in $C^{*}$-modules, J. Math. Anal. Appl. 381 (2011), 546-556.

[2] S. S. Dragomir, A survey on Cauchy-Bunyakovsky-Schwarz type discrete inequalities, J. Inequal. Pure Appl. Math. 4 (2003), Article 63, 142 pp.

[3] R. P. AgARWAL AND S. S. DRAGOMIR, A survey of Jensen type inequalities for functions of selfadjoint operators in Hilbert spaces, Comput. Math. Appl. 59 (2010), 3785-3812.

[4] Y. J. Cho, S. S. Dragomir, C. E. M. Pearce And S. S. Kim, Cauchy-Schwarz functionals, Bull. Austral. Math. Soc. 62(2000), 479-491.

[5] S. S. DRAGOMIR, Čebyšev's type inequalities for functions of selfadjoint operators in Hilbert spaces, Linear Multilinear Algebra 58 (2010), 805-814.

[6] S. S. DRAGOMIR, Vector and operator trapezoidal type inequalities for continuous functions of selfadjoint operators in Hilbert spaces, Electron. J. Linear Algebra 22 (2011), 161-178.

[7] S. S. DRAGOMIR, Ostrowskis type inequalities for continuous functions of selfadjoint operators on Hilbert spaces: a survey of recent results, Ann. Funct. Anal. 2 (2011), 139-205.

[8] S. S. Dragomir, Some new Grüss' type inequalities for functions of selfadjoint operators in Hilbert spaces, Preprint, RGMIA Res. Rep. Coll. 11 (2008), Suplement. Art. 12, http://rgmia.org/v11(E).php.

[9] S. S. Dragomir, Y. J. Cho And S. S. Kim, Some inequalities in inner product spaces related to the generalized triangle inequality, Appl. Math. Comput. 217 (2011), 7462-7468.

[10] S. S. DragomiR, Y. J. CHO AND J. K. KIM, Subadditivity of some functionals associated to Jensen's inequality with applications, Taiwan. J. Math. 15 (2011), 1815-1828.

[11] J. I. FUJII, Operator-valued inner product and operator inequalities, Banach J. Math. Anal. 2 (2008), $59-67$.

[12] J. I. FujiI, M. FujiI, M. S. Moslehian AND Y. Seo, Cauchy-Schwarz inequality in semi-inner product $C^{*}$-modules via polar decomposition, J. Math. Anal. Appl. 394 (2012), no. 2, 835-840.

[13] M. FujiI, S. Izumino, R. Nakamoto and Y. Seo, Operator inequalities related to CauchySchwarz and Hölder-McCarthy inequalities, Nihonkai Math. J. 8 (1997), 117-122.

[14] T. Furuta, J. MićIć Hot, J. PeČArić And Y. SeO, Mond-Pečarić Method in Operator Inequalities, Inequalities for Bounded Selfadjoint Operators on a Hilbert Space, Element, Zagreb, 2005.

[15] D. ILIŠEVIĆ AND S. VAROŠANEC, On the Cauchy-Schwarz inequality and its reverse in semi-inner product $C^{*}$-modules, Banach J. Math. Anal. 1 (2007), 78-84. 
[16] M. S. Klamkin and R. G. Mclenaghan, An ellipse inequality, Math. Mag. 50 (1977), 261-263.

[17] C. S. Lin AND Y. J. CHO, On Holder-McCarthy-type inequalities with power, J. Korean Math. Soc. 39 (2002), 351-361.

[18] C. S. LiN AND Y. J. CHo, On norm inequalities of operators on Hilbert spaces, 2 (2003), 165-173, Inequality Theory and Applications, edited by Y. J. Cho, J. K. Kim and S. S. Dragomir, Nova Science Publishers, Inc., New York, 2003.

[19] C. S. Lin AND Y. J. Cho, Characteristic property for inequalities of bounded linear operators, 4 (2007), 85-92, Inequality Theory and Applications, edited by Y. J. Cho, J. K. Kim and S. S. Dargomir,

[20] M. S. Moslehian AND L.-E. Persson, Reverse Cauchy-Schwarz inequalities for positive $C^{*}$ valued sesquilinear forms, Math. Inequal. Appl. 12 (2009), 701-709.

[21] G. J. Murphy, C* -algebras and Operator Theory, Academic Press, Boston, 1990.

[22] N. OzEKI, On the estimation of the inequalities by the maximum, or minimum values, J. College Arts Sci. Chiba Univ. 5 (1969), 199-203.

[23] G. Pólya And G. Szegö, Aufgaben und Lehrsïze aus der Analysis. Band 1: Reihen, Integralrechnung, Funktionentheorie (in German), 4th Ed., Springer-Verlag, Berlin, 1970 (original version: Julius Springer Berlin, 1925). 